\title{
МЕДИЙНО ОБРАЗОВАНИЕ ЗА ДЕЦА: ПРЕДИЗВИКАТЕЛСТВАТА НА НОВОТО ДИГИТАЛНО ОБЩЕСТВО
}

\author{
Катя Стоянова \\ Софийски университет „Св. Климент Охридски“
}

\begin{abstract}
Резюме. В статията се разглежда медийното и дигиталното образование като необходимо условие за прилагане на съвременните тенденции в образователната система и адаптирането ѝ към потребностите и спецификите на дигиталното общество на XXI век. Лансира се идеята то да започва от предучилищна възраст, когато децата вече целенасочено взаимодействат с различни медийни продукти. Поставен е акцент върху разбирането за дигиталната и медийната грамотност отвъд техническата способност за боравене с медийни продукти, която сама по себе си е важен, но недостатъчен елемент в набора от знания и умения, необходими за разбиране, овладяване и участие в необятната и постоянно променяща се медийна среда.
\end{abstract}

Ключови думи: медийна педагогика; медийна грамотност; медийно образование; дигитална грамотност; критично мислене; креативност

\section{Въведение}

Съвременните деца са потопени в занимания, свързани с популярните медии, новите технологии и културата, от най-ранна възраст. Те израстват в един дигитален свят и развиват много умения, знания и разбиране за него още от раждането си (Marsh 2005).

В свое проучване английският писател и изследовател Дейвид Бъкингам достига до извода, че децата придобиват умения по медийна грамотност дори и при липсата на целенасочени действия от страна на възрастните в тази посока (Buckingham 2007). Към настоящия момент процесът е много по-интензивен не само поради наличието на достатъчно технически ресурси, които са достъпни както от икономическа, така и от техническа гледна точка, но и поради интензивното навлизане на технологиите в живота на съвременния човек в световен мащаб. „Медийната грамотност изисква познания за нас самите, за другите и за световете, в които живеем. Овладяването на технически умения е много по-лесно постижимо за разлика от развиване- 
то на умения за вземане на етични решения или за изразяване на гражданско несъгласие“ (Greenwood 2020, 17).

Според данни на Националния статистически институт ${ }^{1)}$ от април 2020 г. общият дял на домакинствата в България, които имат телевизионни приемници, е 99,4\%; компютри притежават 53,8\%; мобилни телефони 93,3\%; с интернет връзка разполагат 59,5\%. Цифрите показват, че е почти невъзможно да бъдат открити семейства без телевизор или мобилен телефон. Тези проценти неминуемо отбелязват значителен ръст през 2021 г. в резултат на масовото навлизане на дистанционното (онлайн) обучение и дигитализацията във всички сектори на икономиката, предизвикани от пандемията COVID-19: само в края на 2020 г. процентьт на домакинствата с интернет връзка се е увеличил с 19,4\%. Медиите се превръщат в неизменна част от съвременното общество, прониквайки с ускорени темпове и в една сравнително консервативна система като образованието в резултат на извънредната пандемична ситуация. Важно е да отбележим, че боравенето с дигитални и медийни продукти (,,технически познания“) не включва задължително наличието на медийна грамотност, а е само един от инструментите за нейното постигане. Оставането единствено на нивото на техническите познания в тази област може „да отвори кутията на Пандора“ поради заплахите, които глобалната мрежа крие, докато придобиването на знания за медиите - механизъм на създаване, разграничаване на лично и обществено пространство, разбиране и безопасно ползване - има амбициозната и нелека задача „да отвори рога на изобилието“.

\section{Децата и медиите}

Дейвид Бъкингам определя медийното образование като процес на преподаване и учене за медиите, а медийната грамотност - като негов резултат (знанието и уменията, които учениците получават) (Buckingham 2007). Съгласно дефиницията на Съвета на Европейския съюз ${ }^{2}$ основната цел на този вид образование е да развива критичното мислене и активното поведение на учениците. Медийното образование дава възможност на децата още в ранна възраст да се опитват да вземат информирани решения, да „разчитат“, оценяват и създават медийни послания. Чрез медийното образование децата са провокирани да мислят, достигайки сами до съответните отговори, т.е. учат се как, а не какво да мислят. Това, от своя страна, дава възможност за проявата на още едно важно качество - креативност. Медийното образование овластява учениците и се превръща в поле за изява на различни умения, таланти и интереси. Според Грийнууд нашето познание за културата се базира на начина, по който разбираме взаимовръзките от символи и знаци в една по-широка културна екосистема, която включва литература, изкуство, мода, фотография, музика, филми, телевизия и вир- 
туална реалност. „Запасьт от медийни артефакти и символи, чрез които възприемаме света, е безкраен и понякога обезсърчаващ и точно в това се крие нуждата от медийна грамотност“ (Greenwood 2020, 14). Разчитането на медийните послания изисква конкретни познания и умения, които се създават по-лесно и по-ефективно в предучилищна възраст, когато децата напълно естествено възприемат техните източници, тъй като представляват част от естествената им среда.

Още през 2007 г. Бъкингам споделя идеята, че детството, което познаваме, изчезва, като медиите имат основна вина за това. От друга страна, те се превръщат в средство за либерализиране на децата, създавайки едно ново, „електронно поколение“, което е по-отворено, по-демократично и по-осведомено в сравнение с поколението на техните родители.

\section{Ранно начало на медийното образование - причини и аргументи}

Медийните устройства и технологии са в състояние да повлияят цялостно върху живота на хората, но в каква степен и с каква полезност, зависи изцяло от самите ползватели. Създаването на здравословни навици, както и правилното боравене с медийните средства е важно да бъде заложено в ранното обучение, за да не се налага впоследствие по-сложният и не толкова ефективен процес на „отучване“ от създадените погрешни, а нерядко и опасни привички. Този процес предполага познания, регулация и подготовка на специалисти, които да предадат нужните знания и умения, както и повишаване на компетенциите на бъдещите учители за развиване на ранната дигитална и медийна грамотност на децата в предучилищна и начална училищна възраст, включваща разбиране на разликата между лична и публична информация. Децата не се замислят и често са склонни да споделят данни за себе си и своите близки, които биха могли да нарушат неприкосновеността на личното им пространство и да ги направят уязвими. Предизвикателството е в това да се осигури техническата обезпеченост, както и да се открият най-подходящите форми и среда, които да дадат възможност на учениците да овладеят необходимите знания и да придобият полезни навици и умения за критично и креативно взаимодействие със съвременната медийна среда.

През 2020 г., чрез допълнение в Закона за предучилищното и училищното образование ${ }^{3)}$, беше въведено задължително дистанционно обучение, което ускори процеса на дигитализация на образователната система в нашата страна. Принудителната социална изолация по време на пандемията (2020 - 2021 г.) създаде предпоставки за разгръщане възможностите на средствата за масова информация, социалните мрежи и интернет базираните платформи, превръщайки ги в основни пространства за работа, учене, култура, лична и обществена комуникация. Рестрикциите по отношение на 
свободното движение и непосредственото общуване между хората форсира процеса на внедряване на инструментите на съвременното дигитално общество. Пандемията COVID-19 провокира промяна в актуалния дневен ред, поставяйки редица въпроси, като: безопасен интернет, защита на децата от кибертормоз, умерена употреба на дигиталните устройства, реформа на образователната система, ускорен преход от пожелателни предписания към задължителни задачи и тяхното незабавно прилагане.

Още през 2007 г. в книгата си „Медийно образование: грамотност, учене, съвременна култура“ Дейвид Бъкингам описва децата във Великобритания като по-ограничени в рамките на домовете си и много по-малко независими в движението си, отколкото са били майките и бащите им двайсет години по-рано. Също така обръща внимание на факта, че родителите прекарват все по-малко време с децата си, което компенсират, осигурявайки им повече материални придобивки. Констатирана е и огромната културна промяна, която се наблюдава у подрастващите: развиват се побързо физически, започват да правят секс по-рано, все по-често стават извършители на незаконни действия и не на последно място - наблюдава се прогресивно нарастване на употребата на наркотици в ученическа възраст. Тези процеси формират статуса на децата като отделна социална група, което повдига въпроса, от една страна, за нуждата им от защита, от друга - за изключително трудните опити за справяне с осезаемото „рухване“ на дисциплината. Положението на децата във Великобритания, описано от Бъкингам през 2007 г., изглежда като прозорливо предсказание за процесите, които се наблюдават и в развитието на част от на децата в съвременна България.

\section{Изразни средства на медийното образование}

Традиционната образователна система изпитва чувствителен недостиг на ресурси за справяне с редица проблеми: липса на интерес към ученето, хиперактивност, недостиг на концентрация, отсъствие на индивидуален подход, ограничаваща среда на класната стая и др. Медийната грамотност може да овласти децата и да им създаде механизми за защита, като едновременно с това разшири полето им на действие във и извън учебния процес. Медийната педагогика борави с най-новите средства за комуникация и с разнообразието от изразни средства, като целта е децата да извършват с желание всички дейности от учебния процес. Слушането, четенето, решаването на задачи, рисуването, дори пеенето и физическата активност са много по-различни от познатата им традиционна форма на проява. Обогатяването на изразните средства, онлайн достъпът до културни прояви, музеи и галерии, както и виртуалните класни стаи водят до цялостна промяна във формата и съдържанието на доскорошните учебни предмети. 
Децата са провокирани да търсят и намират, да проверяват, изследват и създават, т.е. със своите изисквания и нужди те се превръщат в активни участници в учебния процес. Новите изразни възможности влияят стимулиращо на желанието на децата да учат. Друга положителна страна е възможността за безпрепятствено разпространение на медийните послания, което не зависи от фактори като местоположение, часови пояс или изискване за физическо присъствие. Езиковата бариера също е възможно да бъде преодоляна в голяма част от медийните средства чрез видео, картина, музика и звук, които са универсални и не се нуждаят от превод и адаптация. Резултатът от употребата на новите технологии в образованието зависи преди всичко от това кой, как и с каква цел ги използва. И въпреки утопичното звучене на някои определения за тяхната роля, значително се доближава до реалността твърдение като: „Технологиите ще преобразят ученето, ще овластят учениците и ще предоставят свобода на учителите. Това автоматично ще допринесе за по-активни, креативни, обърнати към ученика форми на образование и всеки, който се противопостави на това, е просто „динозавър“. (Buckingham 2020, 231). Разбира се, подобна реализация е възможна, ако е налице едно демократично общество, което е дигитално и медийно грамотно.

По презумпция основните теми, които се засягат, когато става дума за медийни технологии в образованието, се свеждат до „Безопасност“ и „Заплахи, свързани с тяхната употреба““ (заблуда, измама, кражба на данни, детска порнография и др.). Ограничаването на обсега на медийното образование до степен на предпазване е не само неефективно, но и вредно както за децата, така и за обществото, като цяло. Бягството от предизвикателствата, които поставя новото дигитално общество, не може да бъде решение, а тоталната превенция отнема възможността да се възползваме от всички предимства, които медийното образование е в състояние да даде на учениците в днешния свят.

Медийното обучение при най-малките дава възможност за едновременно усвояване на основните принципи на работа с медийни продукти. Но преди да получат свободата да ги използват, трябва да им се предоставят средства, с които да ги управляват, т.е. трябва да овладеят езика и механизмите за защита на личното си пространство и свобода. Посредством критичен анализ децата преминават от несъзнателно към съзнателно състояние, постепенно изграждайки си система за критично отношение към действителността, както и за информирано и осъзнато вземане на решения. Понякога предучилищната или начална група в училище може да се превърне в ,бойно поле“, на което се отстояват позиции или предпочитания, включително и по отношение на разпределението на ролите в дидактическите упражнения, което е неизбежно. Точно в тази 
възраст децата са по-склонни да се научат както да представят и отстояват собствената си позиция, така и да проявяват толерантно отношение към мнението и предпочитанията на другите - разбира се, с помощта на убедителния, но приятелски тон на преподавателя и при зачитане на равнопоставеността и правото на мнение на всеки. Медийните ресурси в тази област са огромни, благодарение на което децата могат да усвоят трайно полезни умения за провеждане на дискусия. Реалното представяне на действителността на достыпен за децата език развива уменията им за точна оценка на информацията, която получават, респективно способността за критично мислене. Не на последно място, тази дейност може да бъде насочена към самите деца, така че да могат да опознават и развиват себе си, наблюдавайки действията, думите и посланията си и отчитайки въздействието им както върху другите, така и върху самите тях. Не бива да се пропускат социалните, културните, расовите, икономическите и другите различия, които, изниквайки като тема, могат да бъдат разработени за обогатяване на познанията на децата, а не за тяхното противопоставяне.

\section{Децата като обект на медийната индустрия}

Голяма част от индустрията разглежда децата като отделна целева група, тъй като те до голяма степен се превръщат в самостоятелни потребители, които са в състояние да вземат решения за избора и покупката на стоки и услуги. Седемгодишните вече имат право на банкова карта, ползват смартфон и таблет или компютър. Една немалка част от децата разполагат с профили в социалните мрежи, преди да са навършили минималната допустима възраст, която за повечето социални платформи е около 13 години. Определянето на медиите като всемогъща „съзнателна индустрия“, която едностранно налага фалшиви ценности на пасивна аудитория, също е дискусионен въпрос. Бъкингам представя проучвания от 2007 г., според които децата са много по-автономна и критична аудитория в сравнение с традиционното виждане - извод, който категорично се потвърждава и от медийната индустрия. Според него „съвременното образование няма за цел да предпазва младите хора от влиянието на медиите и по този начин да ги заведе на едно по-добро място“, а да им даде възможност да вземат самостоятелни информирани решения и да се научат да поемат отговорност за тях. Бъкингам отбелязва също, че във Великобритания децата започват съзнателно да взаимодействат с медиите още от четиригодишна възраст. Тъй като израстват в изключително компресирана медийна среда, те играят със смартфоните, таблетите и компютрите на родителите си. Телевизията е първият приятел на децата от раждането им, който впоследствие бива изместен от изобретенията на XXI век. „Медийната грамотност е резул- 
татът от медийното образование - знанията и уменията, които учениците придобиват" (Buckingham 2007, 4). Днес този преход - от телевизионния екран към екраните на мобилните устройства - се извършва много по-рано, особено след навлизането на интернет телевизията и възможностите за гледане на предавания на запис.

Тенденцията към съсредоточаване единствено върху заплахите и нежеланите последици от въздействието на медийната среда може да измести акцента на този важен дял от образованието към страховете, породени от симптомите. Подобен подход ограничава възможностите ни да си изградим представа за цялостната картина, което, от своя страна, може да възпрепятства вземането на правилните решения относно развитието на медийното образование. Частичните и временни дейности не само ще затруднят, но и ще забавят значително създаването на подходяща и устойчива система, която изисква както материални, така и интелектуални ресурси: компютри, интернет връзка и разбира се, подготвени преподаватели по дигитална и медийна грамотност, IT специалисти. В този процес съществена роля имат и родителите.

Медийната педагогика е в състояние да създаде у децата положителна нагласа към новите технологии и медиите и по този начин да провокира желанието им да учат. Съвременни медийни продукти като CD-ROM, флашпамет (USB), интерактивни книги, игри, флашкарти, филми, компютърни игри, интернет базирани канали, платформи за учене и много други, включващи множество медийни езици, са предпочитана и търсена от децата форма за развлечение и придобиване на знания.

За успеха на един съвременен концерт са необходими много повече от добри музиканти и озвучаване. Актьорите в театъра трябва да умеят не само да се превъплъщават в различни роли, но и да пеят, да свирят на музикален инструмент, да танцуват. Популярността изисква не само талант, но и умения да привлечеш и да поддържаш интереса на милиони последователи в социалните мрежи, т.е. да бъдеш социално активен. Съвременната аудитория има много по-големи изисквания към изкуството и културата - техните произведения трябва да бъдат цял спектакъл от музика, звук, анимация, шоу, развлечение, емоция, за да привлекат интереса на потребителя. А за децата това важи с още по-голяма сила.

\section{Проучвания на медийното образование за деца}

Проучванията в областта на медийното образование се свеждат до изследване на грамотността на децата и учениците в областта на дигиталномедийните компетенции посредством методологии, които представят не съвсем обективна и цялостна картина. Пандемията от COVID-19 ускори освен въвеждането на онлайн обучението като алтернатива на присъстве- 
ната му форма във всички училища, но постави акцент върху създаването и използването на медийни продукти в образованието. Изследванията в България по отношение на медийното образование и децата сочат, че „интересът на децата към социалните мрежи например остава неизползван от началното образование; за него обучението в училище изгражда по-скоро табута, вместо да търси възможности за впрягане на генерираната от този интерес колосална енергия за целите на учене, преподаване и развитие“ (Danov 2020, 105).

Проучване, проведено по поръчка на Ofcom ${ }^{4)}$ (регулатор на комуникационните услуги във Великобритания) през 2019 г. (Ofcom 2020) достига до следните изводи във връзка с използването на медиите: 1. част от децата подражават на известни лица от социалните медии, като някои от тях имат усещането, че самите те влияят; 2. част от децата предизвикват внимание с публикуване на игрови въпроси или постове със сексуално съдържание, за да привличат внимание; 3. част от децата са виждали смущаващо съдържание, но са успявали да се справят с това. Друга тенденция, наблюдавана в целия възрастов диапазон ( 8 - 17 години), е интересът към YouTube, където се предлага възможност за избор на съдържанието, което да гледат, за сметка на вече остаряващата телевизионна медия.

Според проучване сред деца от предучилищна възраст в Украйна (Yankovych et al. 2019) с цел въвеждане на медийно образование основните причини, които налагат формирането на медийна грамотност, са: 1 . медийната грамотност в предучилищна възраст се възприема от децата като начин на живот; 2. коригирането на погрешни или вредни навици в медийното пространство на по-късна възраст е по-трудно и с по-лош резултат. В проучването изследователите стигат до заключението, че децата са склонни да анализират медийните продукти с родителите и учителите си и проявяват по-голям интерес към списания, книжки, както и желание за създаване на техни собствени медийни продукти. Всички те споделят, че обичат да разговарят за приказните герои и техните постьпки, но изследователите са открили, че има необходимост от по-задълбочен критически анализ, както например дали отразените събития, според мнението на децата, са надеждни. Преди провеждането на експерименталното медийно обучение нито едно от децата не е показало високо ниво на медийна грамотност, а след обучението резултатите сочат следните подобрения в нивото на медийна грамотност: високото ниво от $0 \%$ се е повишило на $15 \%$, а ниското ниво от $36 \%$ е понижено на $26 \%$.

Още през 2005 г. група учени, начело с Бъкингам (Buckingham et al. 2005), проучвайки медийната грамотност сред децата и младите хора, отбелязват следната тенденция: необходимостта от социална теория за медийната грамотност се налага от факта, че тя е най-вече междуличностен 
феномен, в който социалните и личните интереси са неизбежно заложени и представянето същността на медийната грамотност не може да се свежда само до това, което е в детските глави.

Средното тригодишно дете вече е под въздействието на телевизионния екран, на три години прави избор на анимационен филм, а на пет придобива компютърни умения. Тези ресурси носят толкова много информация, която е трудно да бъде овладяна дори и от възрастните, какво остава за децата. Ключът към формиране на медийно грамотни личности, които активно и безопасно да боравят в съвременното медийно пространство, е медийното образование (Yankovych et al. 2019).

\section{Заключение}

Наблюдава се нарастващо безпокойство по отношение на постоянно променящата се медийна среда, както и тенденция да се фокусираме повече върху симптомите, отколкото върху причините на наблюдаваните процеси. Прекомерното вглеждане в страховете не може да бъде работещ подход, тъй като крие риск от задълбочаване на проблемите и нарастваща изолация. Медийното образование не бива да се разглежда като форма на защита, а като процес на подготовка на учениците. Убягва усещането за по-голямата картина, което възпрепятства вземането на правилните решения, болезнено необходими в съвременното дигитално „COVID-19 общество“. Временните решения не могат да бъдат решения за бъдещето - те си остават бързи корекции на вече развил се симптом. Не бива да пропускаме, че това са симптомите на по-мащабни промени, които настъпват не само в медийното пространство, но и във всички сфери - социална, икономическа и политическа - на обществения живот. Медийното образование би могло да запълни част от по-голямата картина. То има добре очертана критична структура (едновременно разбираема и всестранна), която може да бъде разширявана, обхващайки нововъзникнали въпроси. В същото време, медийното образование не е достатъчно само по себе си. То е и ще бъде част от решението на проблема, но също така се нуждае от регулация и реформа. Развиването на медийна грамотност предоставя сравнително демократична алтернатива за регулирането на медийния пазар и тъй като това централно не би могло да се направи, то потребителите е необходимо да го регулират сами (Buckingham 2020). Следва да се постави акцент върху развиване както на критичното, така и на креативното и обърнатото към нуждите на ученика учене - съществен елемент от процеса на адаптиране на образователната система към спецификите на новото дигитално общество на XXI век. 


\section{БЕЛЕЖКИ}

1. Национален статистически институт, [online] [viewed 3 February 2020 and 19 April 2021] Available from: https://www.nsi.bg/

2. Медийна грамотност в дигиталния свят. Резолюция на Европейския парламент от 16 декември 2008 г. относно медийната грамотност в дигиталния свят (2008/2129(INI) (2010/C 45 E/02). Официален вестник на Европейския съюз CE 45/9 [viewed 19 April 2021] Available from: https://eur-lex.europa.eu/ legal-content/BG/ALL/?uri=CELEX\%3A52008IP0598

3. Закон за изменение и допълнение на Закона за предучилищното и училищното образование. Дьржавен вестник, бр. 82 от 18.09.20 г. [viewed 16 February 2021] Available from: https://eur-lex.europa.eu/legal-content/BG/ ALL/?uri=CELEX\%3A52008IP0598

4. Ofcom, [viewed 19 April 2021] Available from: https://www.ofcom.org.uk/ about-ofcom/what-is-ofcom

5. Ofcom. Children's Media Lives, A report for Ofcom. 2020. [viewed 19 April 2021] Available from: https://www.ofcom.org.uk/_data/assets/pdf_file/0021/190524/ cml-year-6-findings.pdf

\section{REFERENCES}

BUCKINGHAM, D., 2020. Epilogue: Rethinking digital literacy: Media education in the age of digital capitalism. Digital Education Review, 37.

BUCKINGHAM, D., 2007. Media education: Literacy, Learning, Contemporary Culture. Cambridge: Polity Press.

BUCKINGHAM, D., BANAJI, S. \& BURN, A. \& CARR D. \& CRANMER, S. \& Willett R., 2005. The Media Literacy of Children and Young People: A review of the research literature on behalf of Ofcom. London: Centre for the Study of Children Youth and Media Institute of Education University of London.

DANOV, D., 2020. Mediyna gramotnost: Preosmislyane na opita. Sofia: Sv. Kliment Ohridski.

GREENWOOD, V., 2020. Navigating Media Literacy: A pedagogical Tour of Disneyland. Gorham: Myers Education Press.

MARSH, J. \& BROOKS, G., HUGHES, J., RITCHIE, L., ROBERTS, S. $\&$ Wright K., 2005. Digital beginnings: Young children's use of popular culture, media and new technologies Sheffield: Literacy Research Centre University of Sheffield.

YANKOVYCH, OL., VOLODYMYR, M., CHAIKA, T., IVANOVA, V., BINYTSKA, K. M., KUZMA, I., PYSARCHUK, OKS. T. AND FALFUSHYNSKA, H. I., 2019. Technology of forming media literacy of children of the senior preschool age of Ukraine. Ternopil: Ternopil Volodymyr Hnatiuk National Pedagogical University. 


\title{
THE MEDIA EDUCATION OF CHILDREN: CHALLENGES FOR THE NEW DIGITAL SOCIETY
}

\begin{abstract}
The paper considers media and digital education as a prerequisite for adopting the new trends in education and adjustment to the needs and specifics of the digital society of the 21 st century. It launches the idea to start teaching children from preschool when they have already interacted purposefully with various media products. Emphasis is on understanding digital and media literacy beyond the technical ability of children to handle media products, which in itself is important but insufficient in the set of knowledge and skills needed to understand, master, and participate in the vast and ever-changing media environment.

Keywords: media pedagogy; media literacy; media education; digital literacy; critical thinking; creativity
\end{abstract}

$\triangle$ Mrs. Katya Stoyanova, PhD Student ORCID ID: 0000-0003-3247-860X Faculty of Educational Studies and the Arts Sofia University Sofia, Bulgaria E-mail: kdstoyanov@uni-sofia.bg 